\title{
Chlamydia trachomatis infections in the female
} rectums

\author{
C I THOMPSON,* A J MACAULAY, $\dagger$ I W SMITH, $\dagger$ \\ From the *Genitourinary Medicine Unit, Department of Medicine, Royal Infirmary, and the $\nmid$ Department of \\ Bacteriology, University of Edinburgh Medical School, Edinburgh, UK
}

SUMMARY One hundred and fifteen consecutive new women patients were examined in a department of genitourinary medicine for evidence of infection with Chlamydia trachomatis in the rectum, in addition to the routine screening tests performed. An impression smear of the rectal mucosa was made as a semiquantitative assessment of the degree of proctitis, and details of bowel habit and symptoms and of sexual practice were noted.

Chlamydial infection was found in the cervices of $15(13 \%)$ and the rectums of six (5\%). Rectal infection was significantly associated with rectal bleeding and microscopic evidence of proctitis, but not with diarrhoea or macroscopic proctitis.

Chlamydia trachomatis has now become widely accepted as being one of the most common sexually transmitted organisms which causes about half the cases of non-gonococcal urethritis (NGU) in men,' and pelvic inflammatory disease and infertility in women. ${ }^{2}$

In women, infections of the rectum with Neisseria gonorrhoeae are known to coexist with cervical infection, and rectums have also been noted as the sole site of infection, which sometimes persists for many months. ${ }^{3}$ Rectal infection is thought to occur as a result of the passive spread of the organism from the vaginal secretions posteriorly towards the anus, facilitated by perineal cleansing procedures. ${ }^{4}$ Gonococcal rectal infections are also well documented in homosexual men, where inoculation is assumed to occur as a result of receptive penoanal intercourse. The prevalence of rectal chlamydial infections has been studied in homosexual men, and is estimated to be 4-8\%. ${ }^{5}$ Little work has been published, however, on the prevalence of rectal chlamydial infections in women, which is estimated at $5-21 \% .^{67}$

The aim of this study was to ascertain the prevalence of rectal chlamydial infections in women attending the Edinburgh genitourinary medicine (GUM) clinic, and to show any association with the presence or absence of symptoms, proctitis, sexual practice, and concurrent gonococcal infection. We compared culture

Address for reprints: Dr C I Thompson, Department of Medicine, Royal Infirmary, Edinburgh EH3 9YW, UK

Accepted for publication 11 May 1989 with direct immunofluorescence to detect chlamydiae in the rectum.

\section{Patients and methods}

Approval for the study was obtained from the Medicine and Clinical Oncology Ethics of Medical Research Sub-Committee of the Lothian Health Board. The patients were consecutive new or "return new" women seen by one of us (CIT) in the department of GUM at Edinburgh Royal Infirmary from 1 June 1987 to 15 February 1988. Excluded from participation were women who were pregnant, who had received antibiotics within the preceding four weeks, or who were considered to be at high risk of acquiring infection with hepatitis B or human immunodeficiency viruses (HIV) (who had any history of intravenous drug misuse or were sexual partners of men who were bisexual or intravenous drug misusers). Informed verbal consent was obtained from 115 women who entered the study.

\section{CLINICAL PROCEDURE}

Each patient gave a history and underwent a general physical examination and detailed genital and pelvic examinations, during which the requisite diagnostic tests were taken. ${ }^{8}$ In addition to the standard screening tests for $\boldsymbol{N}$ gonorrhoeae, $\boldsymbol{C}$ trachomatis, Trichomonas vaginalis, monilia, and Treponema pallidum, blood was taken to test for antibody to chlamydiae. The rectal specimens were taken after inserting a lightly lubricated (with KY jelly, Johnson \& Johnson, 
Slough, Berkshire) disposable proctoscope (Welch Allan, UK), which allowed direct visualisation of the rectal mucosa after the obturator had been removed. The macroscopic appearance of the mucosa was documented according to the system of Watts et al, ${ }^{9}$ and a rectal mucosal impression smear was made using the modified method of Anthonisen and Riis described by McMillan et al. ${ }^{10}$ Still under direct vision, using cotton tipped wooden applicator sticks, the rectal mucosa was gently abraded with two swabs; the first was rubbed onto the well of a teflon coated slide before being inoculated into sucrose phosphate transport medium (2SP) and the second was used directly to inoculate the same 2SP. A third swab was used to obtain faecal material for stool culture. The teflon coated slide was fixed with acetone and stored for collection, and the specimens in 2SP were stored at $-70^{\circ} \mathrm{C}$ within five minutes of being taken and were transported to the laboratory within seven hours. Once the examination was complete, and while awaiting the results of direct microscopy, each patient was asked about travel abroad, sexual practice, bowel habit, recent diarrhoea, rectal bleeding or discharge, or both, and perianal itch. At the end of the consultation, the patient was given a stool specimen container and asked to bring a fresh stool specimen at the next visit. At a return visit, about one month later, the chlamydial serology test was repeated at the same time as the second syphilis serology test.

\section{LABORATORY METHODS \\ C trachomatis}

Specimens were cultured in cycloheximide treated McCoy cells using the method of Thomas et al." The coverslips were incubated for three days at $35^{\circ} \mathrm{C}$ before being stained with iodine to show inclusions that contained glycogen. The rectal specimens were all cultured initially and passed to new cell cultures before being classed as giving negative results.

The smears were stained with Chlamyset (Orion Diagnostica) according to the manufacturer's instructions, and were examined in a Leitz incident light ultraviolet microscope by an experienced technician. The slides were considered to give positive results if at least five typical elementary bodies were seen.

Titrations for IgG antibody to chlamydiae were carried out as described by Richmond and Caul using $\mathrm{L}_{2}$ infected McCoy cells. ${ }^{12}$ The antihuman fluorescein isothiocyanate conjugates were from Wellcome Laboratories, and the slides were examined in a Leitz SM Lux ultraviolet microscope.

\section{$N$ gonorrhoeae}

Specimens were plated direct on to modified New York city medium and incubated at $37^{\circ} \mathrm{C}$ in an atmosphere enriched with carbon dioxide, and bacterial colonies were identified by a rapid carbohydrate utilisation test. ${ }^{13}$

\section{Stool specimen}

The stool specimens were concentrated in ether and stained with iodine, and the wet films were examined for intestinal protozoa.

\section{Mucosal impression smear}

The rectal mucosal impression smears were fixed in absolute methanol for 10 minutes, stained by Giemsa, and mounted in DPX. The number of polymorpho-

Table 1 Patients with rectal infection with Chlamydia trachomatis or Neisseria gonorrhoeae, or both

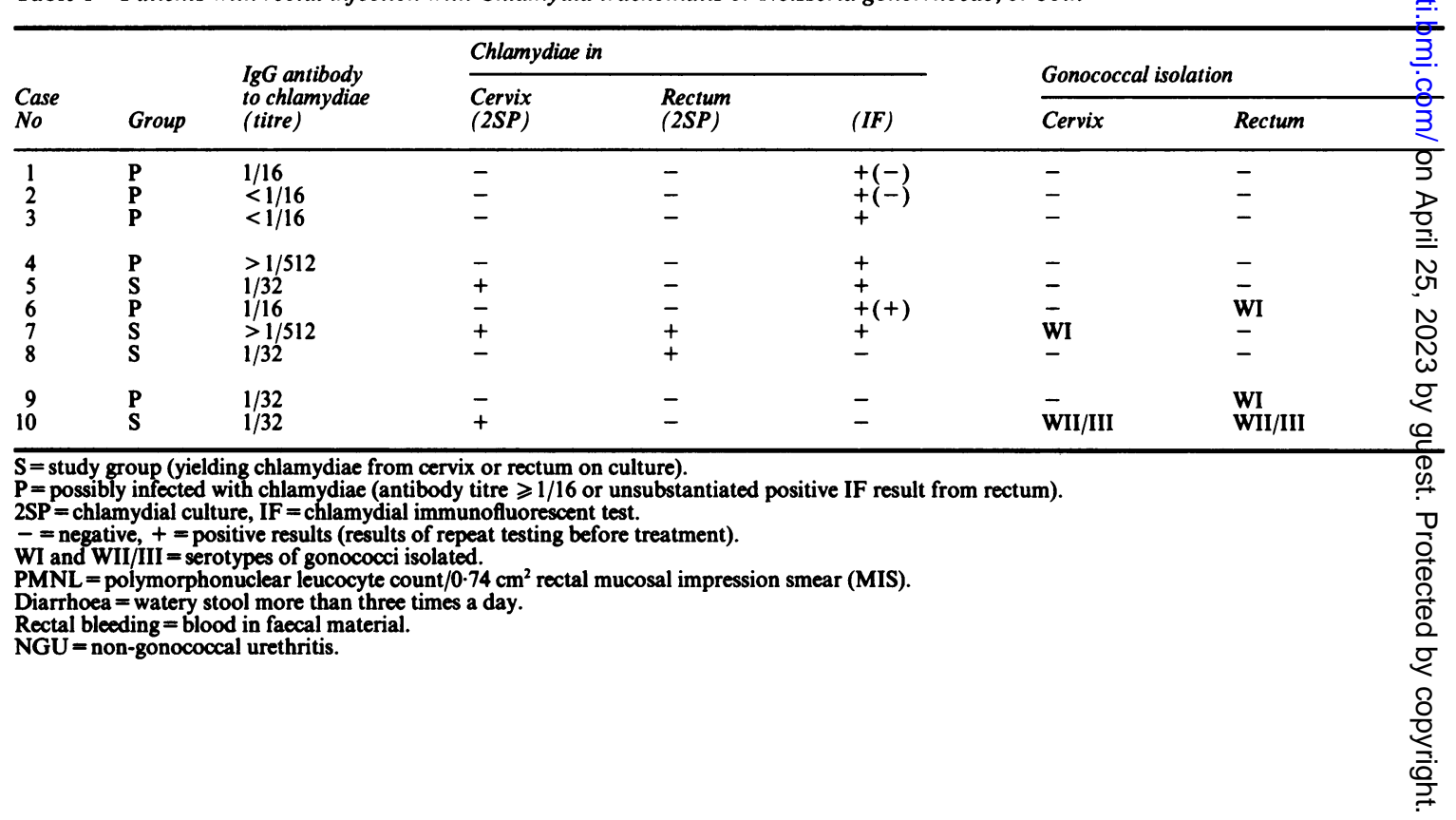


nuclear leucocytes (PMNL) within an area of $0.74 \mathrm{~cm}^{2}$ was counted, and the interquartile range of PMNL was calculated for each group of patients. The number of patients with more than 24 PMNL within the defined area was noted.

\section{STATISTICAL METHOD}

The significance of results of the two by two tables was calculated by Fisher's exact test.

\section{Results}

Of 115 women examined, we excluded 14 (seven because of toxic or contaminated rectal $C$ trachomatis cultures, six because of unsatisfactory rectal mucosal impression smears, and one because no initial antibody titre was obtained), which resulted in 101 patients being studied. Forty two (median age 23) had no evidence of chlamydial infection, with negative culture and immunofluorescence results and chlamydial antibody titres of less than $1 / 16,{ }^{14}$ and therefore formed the control group. Fourteen (median age 20) yielded 15 isolations of $C$ trachomatis by tissue culture (13 from the endocervix and two from the rectum), and these patients constituted the study group. The remaining 45 patients were diagnosed as having possible $C$ trachomatis infection on the basis of a chlamydial antibody titre of $1 / 16$ or more or an unsubstantiated positive result in a rectal immunofluorescence test. The three groups were well matched for numbers of sexual partners in the previous three months (mean 1; range 0-2).

Of the 101 women studied, 22 were sexual contacts of men with NGU (four controls, four in the study group, and 14 in the group with possible infection). Routine stool cultures and microscopy from all patients gave negative results. Seven patients had gonorrhoea, one control (endocervical), three in the study group (three endocervical and one concurrent rectal), and three with possible infection (one endocervical only, two rectal only).

Of 68 patients from whom a second blood sample was obtained for testing for antibody to chlamydiae (23/42 controls, $14 / 14$ in the study group, $31 / 45$ with possible infection) only one showed a significant change in titre, from $1 / 256$ to $1 / 64$. Cultures for $C$ trachomatis and rectal immunofluorescence gave negative results for this patient.

C trachomatis was recovered from the cervices of 13 patients. Rectal cultures from two patients yielded $C$ trachomatis after passage, and the organism was shown by immunofluorescence of the rectal smear from one of these two patients and from a further six patients. Table 1 shows details of the 10 patients with positive rectal results for $C$ trachomatis or $N$ gonorrhoeae, or both.

Table 2 shows the incidence of symptoms and the results of the rectal mucosal impression smears in all 101 women. Table 3 shows the symptoms and results of rectal mucosal impression smears in seven women with rectal infection compared with the controls. Only one patient (case 6) engaged in regular (at least once a month) anal intercourse.

\section{Discussion}

Although the number of patients included in this study was relatively small, the incidences of cervical

\begin{tabular}{|c|c|c|c|c|c|}
\hline $\begin{array}{l}P M N L \\
\text { count } \\
\text { in } M I S\end{array}$ & $\begin{array}{l}\text { Mucosal } \\
\text { appearance }\end{array}$ & Diarrhoea & $\begin{array}{l}\text { Rectal } \\
\text { bleeding }\end{array}$ & $\begin{array}{l}\text { Sexual } \\
\text { contact } \\
\text { of man } \\
\text { with } N G U\end{array}$ & $\begin{array}{l}\text { Anal } \\
\text { intercourse }\end{array}$ \\
\hline $\begin{array}{l}0 \\
0 \\
0\end{array}$ & $\begin{array}{l}\text { Normal } \\
\text { Normal } \\
\text { Normal }\end{array}$ & $\begin{array}{l}\text { No } \\
\text { No } \\
\text { No }\end{array}$ & $\begin{array}{l}\text { No } \\
\text { No } \\
\text { No }\end{array}$ & $\begin{array}{l}\text { No } \\
\text { No } \\
\text { Yes }\end{array}$ & $\begin{array}{l}\text { No } \\
\text { No } \\
\text { No }\end{array}$ \\
\hline $\begin{array}{r}111 \\
0 \\
35 \\
146 \\
145\end{array}$ & $\begin{array}{l}\text { Normal } \\
\text { Normal } \\
\text { Normal } \\
\text { Normal } \\
\text { Normal }\end{array}$ & $\begin{array}{l}\text { No } \\
\text { No } \\
\text { Yes } \\
\text { No } \\
\text { No }\end{array}$ & $\begin{array}{l}\text { No } \\
\text { No } \\
\text { No } \\
\text { Yes } \\
\text { No }\end{array}$ & $\begin{array}{l}\text { Yes } \\
\text { Yes } \\
\text { Yes } \\
\text { No } \\
\text { Yes }\end{array}$ & $\begin{array}{l}\text { No } \\
\text { No } \\
\text { Yes } \\
\text { No } \\
\text { No }\end{array}$ \\
\hline $\begin{array}{r}0 \\
560\end{array}$ & $\begin{array}{l}\text { Normal } \\
\text { Pus }\end{array}$ & $\begin{array}{l}\text { No } \\
\text { Yes }\end{array}$ & $\begin{array}{l}\text { No } \\
\text { Yes }\end{array}$ & $\begin{array}{l}\text { Yes } \\
\text { No }\end{array}$ & $\begin{array}{l}\text { No } \\
\text { No }\end{array}$ \\
\hline
\end{tabular}


Table 2 Age, contact status, symptoms, and results of mucosal impression smears (MIS) of 101 women

\begin{tabular}{|c|c|c|c|c|c|c|}
\hline Group & $\begin{array}{l}\text { Median age } \\
\text { (range) }\end{array}$ & $\begin{array}{l}\text { Sexual } \\
\text { contacts } \\
\text { of men } \\
\text { with } N G U\end{array}$ & $\begin{array}{l}\text { No with } \\
\text { diarrhoea }\end{array}$ & $\begin{array}{l}\text { No with } \\
\text { rectal } \\
\text { bleeding }\end{array}$ & $\begin{array}{l}\text { No with } \\
>24 P M N L \\
\text { in } 0.74 \mathrm{~cm}^{2} \\
M I S\end{array}$ & $\begin{array}{l}\text { Interquartile } \\
\text { range of } P M N L \\
\text { in } M I S\end{array}$ \\
\hline $\begin{array}{l}C(n=42) \\
S(n=14) \\
P(n=45)\end{array}$ & $\begin{array}{l}23(16-47) \\
20(16-35) \\
24(17-41)\end{array}$ & $\begin{array}{r}4 \\
4 \\
14\end{array}$ & $\begin{array}{l}2 \\
2 \\
9\end{array}$ & $\begin{array}{l}1 \\
3 \\
1\end{array}$ & $\begin{array}{l}4 \\
6 \\
7\end{array}$ & $\begin{array}{l}0-0 \\
0-146 \\
0-8\end{array}$ \\
\hline
\end{tabular}

$\mathrm{C}=$ controls (with no evidence of chlamydial infection).

See table 1 for meanings of other abbreviations and definitions.

Table 3 Association of rectal infection (with $C$ trachomatis or $N$ gonorrhoea, or both) with symptoms and findings in rectal mucosal smears (MIS)

\begin{tabular}{llll}
\hline & $\begin{array}{l}\text { No with } \\
\text { diarrhoea }\end{array}$ & $\begin{array}{l}\text { No with } \\
\text { rectal } \\
\text { bleeding }\end{array}$ & $\begin{array}{l}\text { No with } \\
\text { in } 0.74 \mathrm{~cm}^{2} \\
M I S\end{array}$ \\
\hline $\begin{array}{l}\text { Rectal infection } \\
(\mathrm{n}=7)^{*}\end{array}$ & 2 & 2 & 5 \\
$\begin{array}{c}\text { Control group } \\
(\mathrm{n}=42)\end{array}$ & 2 & 1 & 4 \\
$\begin{array}{l}\text { Difference } \\
\text { (f) }\end{array}$ & $\mathrm{p}=0.09$ & $\mathrm{p}=0.05$ & $\mathrm{p}=0.001$ \\
\hline
\end{tabular}

*Excludes cases 1, 2, and 3 (table 1) for whom rectal infection was not substantiated.

See table 1 for meanings of other abbreviations and definitions.

chlamydial infection (13\%) and gonorrhoea (7\%) were very similar to those found in 1987 , which were $10 \%$ for chlamydial infection and $7 \%$ for gonorrhoea. As seen in table 1, only one patient had rectal $C$ trachomatis detected by both culture and immunofluorescence. Three of the seven patients who had a positive rectal immunofluorescence test result at the initial visit had the test repeated before being treated. On repeat testing two (cases 1 and 2) gave negative results and the third (case 6) was confirmed as having a positive result. Three patients (cases 1,2, and 3) had no other data to support the diagnosis of rectal $C$ trachomatis infection, although one (case 3 ) had sexual contact with NGU. We think that these three patients had to be considered to have given possible false positive results, and we therefore excluded them from further analyses. As case 4 had a concurrent chlamydial antibody titre of $>1 / 512$, case 5 had a coexistent endocervical $C$ trachomatis infection, and case 6 had a positive immunofluorescence test result that was confirmed on repeat testing, these immunofluorescence results have been assumed to represent true positive results, despite the lack of confirmation by culture.

Culture is generally taken as being the "gold standard" for diagnosing chlamydial infection, and we used a double inoculation technique to increase the yield. ${ }^{15}$ Despite all the rectal specimens being passed once, however, our results failed to agree with those of
Rompalo et al, who used immunofluorescence to detect the $C$ trachomatis inclusions in cell culture and achieved $90 \%$ sensitivity and $100 \%$ specificity when comparing immunofluorescence with culture for diagnosing rectal infections. ${ }^{16}$ Comparison of immunofluorescence with culture of routine cervical and urethral specimens from unselected GUM patients in this laboratory produced a sensitivity of $100 \%$ and specificity of $98 \%$ (unpublished data), but in this study immunofluorescence had a sensitivity of only $50 \%$ and specificity of $93 \%$ compared with culture. Treharne and Forsey speculated that local antibody can interfere with the isolation of $C$ trachomatis by culture, ${ }^{14}$ which may possibly explain why culture did not confirm immunofluorescence results in this study. We did not measure secretory antibody concentrations.

Another problem is the interpretation of results of the immunofluorescence test on rectal material, which is difficult even for experienced technicians because of the assorted bacteria and faecal material in the specimens. In a future study this problem might be overcome by submitting two smears, the second being blocked by homologous antibody before being stained with the immunofluorescent reagents. Comparison of the two preparations might then confirm the presence of $C$ trachomatis. For a similar reason, an enzyme linked immunosorbent assay (ELISA) was not used to detect $C$ trachomatis because of the high possibility of false positive results caused by other bacteria. A competitive inhibition (blocking) assay (ABBOTT) is now available to confirm any ELISA positive results, however, and this test would merit assessment in any future study as it is less subjective than immunofluorescence.

The lack of appreciable change in the titre of IgG antibody to chlamydiae agrees with most observations on the serology of genital chlamydial infections. ${ }^{14}$ The results here may not all reflect infection with $C$ trachomatis, as the antibody measured was the group antibody to the genus chlamydia, and these patients may have had an infection such as TWAR (Chlamydia pneumoniae) in the past.

In view of the small numbers obtained, we did not attempt to type the $C$ trachomatis isolates. Serotypes $L_{1}, L_{2}$, and $L_{3}$ are known to produce severe proctitis, 
whereas infection with the oculogenital strains results in much milder disease. ${ }^{17}$ Barnes et al also noted that the predominant serotype was $D / D^{\prime}$ in a group of homosexual men, whereas in the endocervix the predominant infection was with serotype E. ${ }^{18}$ The incidence of rectal chlamydial infection was $5 \%$, and only two $(\mathbf{4 0} \%)$ of those five patients had coexisting cervical infection. In all but one patient, rectal infection (with either $C$ trachomatis or $N$ gonorrhoeae) did not appear to be related to the practice of anal intercourse, and infection must be assumed to have occurred by passive spread from the vulva.

One of the aims of the study was to measure the degree of proctitis by the PMNL count in the mucosal impression smear. Our results show that relatively minor degrees of proctitis may appear normal macroscopically, and may also be asymptomatic. Seven patients, four in the control group and three in the study group, in whom no rectal infection was shown had more than 24 PMNL per $0.74 \mathrm{~cm}^{2}$ in the mucosal impression smear. The PMNL counts found in five patients (cases 4, 6, 7, 8, and 10) were therefore not necessarily caused by the infections found. In one patient (case 6) it was possible to repeat the mucosal impression smear after treatment with erythromycin, when the PMNL count was shown to be zero. This does not exclude the presence of other undetected pathogens sensitive to erythromycin. For various reasons it was not possible to repeat the mucosal impression smear for the other four patients with high PMNL counts, but an appreciable association was seen between high PMNL counts and rectal infection with $C$ trachomatis or $N$ gonorrhoeae.

Rectal infection (with either $C$ trachomatis or $N$ gonorrhoeae) was not associated with diarrhoea, but was associated with blood in the faecal material. The occurrence of this symptom should therefore prompt rectal examination, and testing for rectal $C$ trachomatis infection, in addition to routine culture for $N$ gonorrhoeae. The lack of symptoms in most cases, however, might result in rectal $C$ trachomatis infections persisting untreated.

It would be interesting to conduct a larger study of a similar nature to match serotype with site of infection, symptoms, and objective semiquantitative evidence of proctitis.
Financial assistance was received from the Department of Medicine of the University of Edinburgh for the statistical analyses. We thank Dr H Young, department of bacteriology, for the gonococcal and stool cultures performed on each patient, and Mrs Moira Fairgrieve for her assistance in the collection of the clinical material.

\section{References}

1 Oriel JD, Ridgway GL. Genital infection in men. Br Med Bull 1983;39:133-7.

2 Weström L, Mårdh P-A. Chlamydial salpingitis. Br Med Bull 1983;39:145-50.

3 Bhattacharyya MN, Jephcott AE. Diagnosis of gonorrhoea in women: role of the rectal sample. British Journal of Venereal Diseases 1974;50:109-12.

4 Kinghorn GR, Rashid S. Prevalence of rectal and pharyngeal infection in women with gonorrhoea in Sheffield. British Journal of Venereal Diseases 1979;55:408-10.

5 Munday PE, Taylor-Robinson D. Chlaymdial infection in proctitis and Crohn's disease. $\mathrm{Br}$ Med Bull 1983;39:155-8.

6 Jones RB, Rabinovitch RA, Katz BP, et al. Chlamydia trachomatis in the pharynx and rectum of heterosexual patients at risk for genital infection. Ann Intern Med 1985;102:757-62.

7 Stamm WE, Quinn TC, Mkrtichian E-C, Wang SP, Schuffler MD, Holmes KK. Chlamydia trachomatis proctitis. In: Mårdh P-A, Holmes KK, Oriel JD, Piot P, Schachter J, eds. Chlamydial infections. Amsterdam: Elsevier Biomedical Press, 1982:111-4.

8 Robertson DHH, McMillan A, Young H. In: Clinical practice in sexually transmissible diseases. Edinburgh: Churchill Livingstone, 1989:92-107.

9 Watts JMcK, Thompson H, Goligher JC. Sigmoidoscopy and cytology in the detection of microscopic disease of the rectal mucosa in ulcerative colitis, Gut 1966;7:288-94.

10 McMillan A, Gilmour HM, Slatford K, McNeillage GJC. Proctitis in homosexual men: a diagnostic problem. British Journal of Venereal Diseases 1983;59:260-4.

11 Thomas BJ, Evans RT, Hutchison GR, Taylor-Robinson D. Early detection of chlamydial inclusions combining the use of cycloheximide-treated McCoy cells and immunofluorescent staining. J Clin Microbiol 1977;6:285-92.

12 Richmond SJ, Caul EO. Fluorescent antibody studies in chlamydial infection. J Clin Microbiol 1975;1:345-52.

13 Robertson DHH, McMillan A, Young H. In: Clinical practice in sexually transmissible diseases. Edinburgh: Churchill Livingstone, 1989:201-14.

14 Treharne JD, Forsey T. Chlamydial serology. Br Med Bull 1983;39:194-200.

15 Dunlop EMC, Goh BT, Darougar S, Woodland R. Triple culture tests for diagnosis of chlamydial infection of the female genital tract. Sex Transm Dis 1985;12:68-71.

16 Rompalo AM, Suchland RJ, Price CB, Stamm WE. Rapid diagnosis of Chlamydia trachomatis rectal infection by direct immunofluorescence staining. J Infect Dis 1987;155:1075.

17 Quinn TC, Goodell SE, Mkrtichian E-C, et al. Chlamydia trachomatis proctitis. N Engl J Med 1981;305:195-200.

18 Barnes RC, Rompalo AM, Stamm WE. Comparison of Chlamydia trachomatis serovars causing rectal and cervical infections. J Infect Dis 1987;156:953-8. 